\section{Asia-Pacific Journal of Management and Technology}

Online ISSN: $2652-6840$

www.ajmt.org

Original Article

\title{
An Initiative to Make Shopping Hassle Free for Individuals with ASD Steps Towards Sustainable Development
}

\author{
Mitu De ${ }^{1^{\star}}$, Indrani Basu², Vineet Saraiwala ${ }^{3}$ \\ ${ }^{1}$ Department of Botany, Gurudas College, Kolkata 700054 \& Autism Society, Kolkata 700099, India. \\ ${ }^{2}$ Autism Society, Kolkata 700099, India \\ ${ }^{3}$ Big Bazaar, Kolkata, West Bengal, India. \\ ${ }^{*}$ Correspondence E-mail:mitude@rediffmail.com
}

\begin{abstract}
The United Nations Development Programme's (UNDP) 2030 Agenda for Sustainable Development and its 17 Sustainable Development Goals (SDGs) provide a powerful framework for guiding local communities, countries, and the international community toward disability-inclusive development. Accessible, well-designed, and maintained public space is critical to the health of any city. Yet public spaces are generally created for an ideal individual without disability or limitation. Reasonable accommodations and support systems must be in place for all disabilities more so for invisible disabilities. In the urban environment, there are very few places for individuals with Autism Spectrum Disorder (ASD) to congregate and socialize. For most individuals with ASD and their families, shopping in malls, an activity that most of us take for granted, become so challenging that they often avoid it. In this paper we discuss how the retail giant Big Bazaar addressed this issue and took some major steps to make shopping in their outlets a hassle free, happy experience for individuals with ASD. Big Bazaar has made its stores accessible to people with disabilities by implementing disabilityfriendly accessibility programs and infrastructure improvements. This initiative was based on their larger philosophy on inclusion and empowerment of people with disabilities. It is part of the new mantra coined at Big Bazaar to incorporate the philosophy of "Sabke Liye" meaning 'for everyone'. Big Bazaar launched Autism Quiet Hour in April 2019 and it has been a regular feature every Tuesday. Several measures are taken during this duration so that the shopping area is autism friendly. Autism Society West Bengal (ASWB) was the NGO partner of Big Bazaar in Kolkata and was active in the awareness and sensitization program prior to the launch of Autism Quiet Hour in two outlets of Big Bazaar in Kolkata. In this paper we will also discuss about the measures that Big Bazaar took to make the shopping experience for individuals with autism a happy one.
\end{abstract}

Keywords: Autism Quiet Hour; Big Bazaar; Accessibility; Reasonable Accommodations

\section{Introduction}

Accessible, well-designed, and maintained public space is critical to the health of any city. Yet public spaces are generally created for an ideal individual without disability or limitation. Public space belongs to all; it is the right of every citizen. Yet people with a disability, who are stakeholders in society, are often excluded from this right. Despite the international community's clear commitment to a 2030 Development Agenda that is inclusive, open, and sustainable, persons with disabilities continue to face significant barriers to full inclusion and involvement in society and development. 


\section{Sustainable Development Goals (SDGs)}

The United Nations Development Programme's (UNDP) 2030 Agenda for Sustainable Development and its 17 Sustainable Development Goals (SDGs) provide a powerful framework for guiding local communities, countries, and the international community toward disability-inclusive development. The post-2015 intergovernmental negotiations resulted in the 2030 Agenda. The 2030 Agenda is a 35-page document that is divided into five parts. Since the Millennium Development Goals (MDGs) did not include people with disabilities, they were left out of several development programs and funding sources. Persons with disabilities, on the other hand, are included in the 2030 Agenda.

The SDGs are a useful focus for improving accessibility for persons with disabilities, as well as improving accessibility for all in our societies. That SDGs have taken on the principle of "leave no one behind" to reinforce that the SDGs are applicable for all. At the heart of this is accessibility - disabled people's willingness to participate in and contribute to debates and adoption of the SDGs. Human settlements must be inclusive, peaceful, and durable, according to Goal 11 on Sustainable Cities and Communities. This has clear implications for people with disabilities requiring our cities and communities to embrace accessibility as a key part of making our cities inclusive, safe, and resilient.

People with various disabilities must be able to access the built environment and public space in a self-sufficient and equitable manner. Universal design concepts must be used in the planning and implementation of cities and buildings.

\section{Universal design}

Buildings and landscapes can be built to meet the needs of all users thanks to universal design, which puts human diversity at the centre of the design process. As a result, it applies to anyone, regardless of age or size, as well as anyone with any physical, sensory, mental health, or intellectual capacity or impairment. It is about achieving good design so that people can navigate, use, and appreciate the world to the greatest extent possible, in the most self-sufficient and natural way possible, without the need for modifications or specialized solutions.

By incorporating disability into the implementation of Agenda 2030 and its SDGs, the likelihood of goods, facilities, and environments being more affordable, useful, and sustainable for everyone is increased, which benefits people with disabilities in their daily lives. Universal design is now a key element of the SDG as a means of including people with disability. The SDG are interconnected, and the aim is to "leave no one behind" Everything that is designed and produced should be done in a way so that every person is able to use it. The Universal Design concept implies not only introduction of smart, but universal solutions also that would bring benefits for all citizens. It is also an essential contributing factor to human rights, social equality, and equal opportunities as well as to the Sustainable Development Goals, one of which is dedicated to Reduced inequalities (Goal 10).

\section{Reasonable accommodations}

An appropriate accommodation is a change made to a system to accommodate or make a system more equitable for a person with a demonstrated need. Individuals with ASD, like anyone else with a disability, can need accommodations to perform the essential functions of the job they want or have. Since there is no definitive list of fair accommodations, each case must be assessed on its own merits. Reasonable accommodations and support systems must be in place for all disabilities more so for invisible disabilities.

\section{Accessible urban space for individuals with autism in Retail environments}

Retail environments will help people fulfil their everyday shopping and food needs regardless of whether they have access to private transportation. Both retail establishments and related public spaces should be uniformly built to provide consumers and workers with equal access. "Some of the functioning inaccessible to persons with disabilities are unavailable not because they suffer from physical impairments, but because social institutions 
are set up to improve the functioning of the normally abled but not of persons with disabilities", according to Walker and Unterhalter (2007).

\section{Challenges for shoppers with autism}

According to the DSM-5, autism spectrum disorder (ASD) is a dynamic neurodevelopmental disorder marked by chronic deficiencies in social communication and interaction, as well as stereotyped attitudes, desires, and activities (American Psychiatric Association, 2013). Communication problems, difficulty of social interactions and creative play, and behavioral symptoms such as repetitive behaviors and/or a limited range of interests in activities are all symptoms of autism spectrum disorder (Cohen, 1997). Autism Spectrum Disorder (ASD) occurs when the brain develops abnormally and has difficulty performing a critical function: making sense of the world. ASD can be found in any country, ethnic group, or socioeconomic class (Daley, 2002). Individuals with ASD-related characteristics should be present in equal numbers across cultures (Grinker, 2008), and epidemiological rates should be similar in different parts of the world. According to prevalence rates in the West, India's ASD population is projected to be between 2 and 4 million people.

Since autism is a spectrum disorder, the obstacles that people with autism face when trying to enter public spaces differ and are difficult to predict. Overly bright or dark room, noisy and abrupt announcements, or audio that is activated without warning can all be difficult in crowded, busy environments. For autistic people, navigating public spaces may be a difficult task. For autistic people who have a very literal understanding of language, the unwritten rules of what you can and cannot touch can be difficult to understand.

In the urban environment, there are very few places for individuals with Autism Spectrum Disorder (ASD) to congregate and socialize. For most individuals with ASD and their families, shopping in malls, an activity that most of us take for granted, become so challenging that they often avoid it. The noise that is usually associated with shopping malls along with the announcements over the public address system, bright lights, twinkling lights often trigger extreme uneasiness among autistic people. It causes a sensory overload that may lead to extreme behavioural issues also known as 'meltdowns'.

\section{Autism Quiet Hour at Big Bazaar}

The Indian retail giant Big Bazaar addressed this issue and took some major steps to make shopping in their outlets a hassle free, happy experience for individuals with ASD.

Big Bazaar has made its stores accessible to people with disabilities by implementing disability-friendly accessibility programs and infrastructure improvements. This initiative was based on their larger philosophy on inclusion and empowerment of people with disabilities. It is part of the new mantra coined at Big Bazaar to incorporate the philosophy of "Sabke Liye" meaning 'for everyone'. Big Bazaar launched Autism Quiet Hour inApril 2019 in 23 outlets across India and it has been a regular feature every Tuesday. These designated Quiet Hours were for people with autism and other developmental disorders and their family members/caregivers to enjoy a sensory-friendly shopping experience. Autism Society West Bengal (ASWB) was the NGO partner of Big Bazaar in Kolkata and was active in the awareness and sensitization program prior to the launch of Autism Quiet Hour in two outlets of Big Bazaar in Kolkata. Several measures are taken during this duration so that the shopping area is autism friendly.

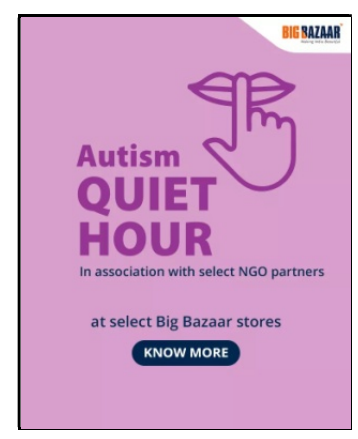

Fig 1a. Autism Quiet Hour advertisement

Ensuring it all flows seamlessly was the sensitised staff. Before the launch of the "Autism Quiet Hour" the NGO partners took several sessions with the Big Bazaar staff so that they were sensitized about autism. So, 
there were no judging eyes whether they were spinning, rocking, or hand-flapping while they shopped. The initiative was rolled out by Big Bazaar in April 2019 after considerable thought, time, and effort. Only select outlets of Big Bazaar were selected in different countries (Fig. 1).

\section{Reasonable accommodations provided during 'Autism Quiet Hour.'}

As individuals with autism shopped at the select Big Bazaar outlets during "Autism Quiet Hour," the sensory overload was minimized, lights were dimmed, announcements were halted, no music was played, cash registers did not ring, and trolley movements were reduced. (Fig. 1a). The aisles were all clutter free. There is a safe play area too where parents to leave their kids and shop without a worry. The Big Bazaar staff arranged for some activities with which the young kids could be engaged while their parents shopped. There were ample seating areas for the shoppers. There were priority billing counters for autistic shoppers as many people with autism may have issues if they have to wait for too long in the billing queues.

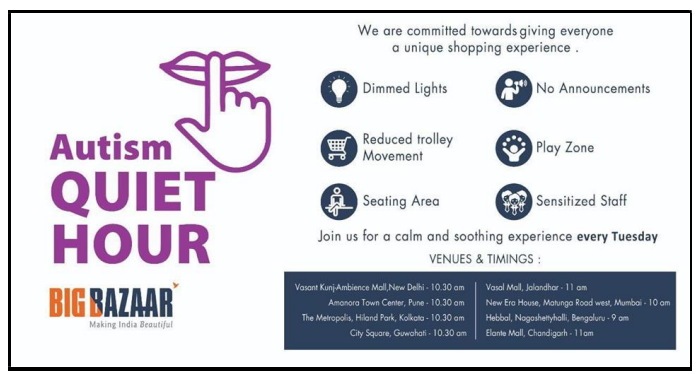

Fig. 1a. Autism Quiet Hour detailed advertisement with the reasonable accommodations

\section{Discussion}

To make the shopping experience at Big Bazaar a happy and hassle free one the retail giant kept in mind the strengths of individuals with autism. Most autistic individuals are visual learners. Pictures or visuals give more clarity than text messages, so they understand what to expect. Every area was labelled appropriately so that the autistic shoppers knew what to expect. Sometimes there was a picture drawn along with the label for more clarity (Fig. 2 \& 3 ).

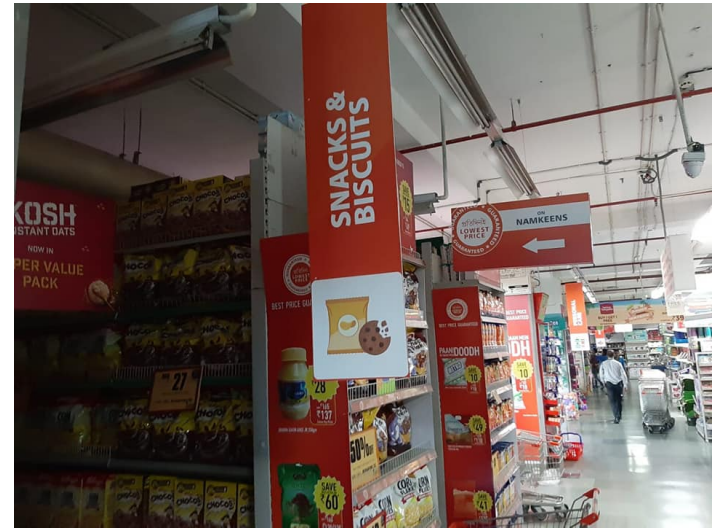

Fig. 2. Graphics used to indicate the Snacks and biscuits aisle

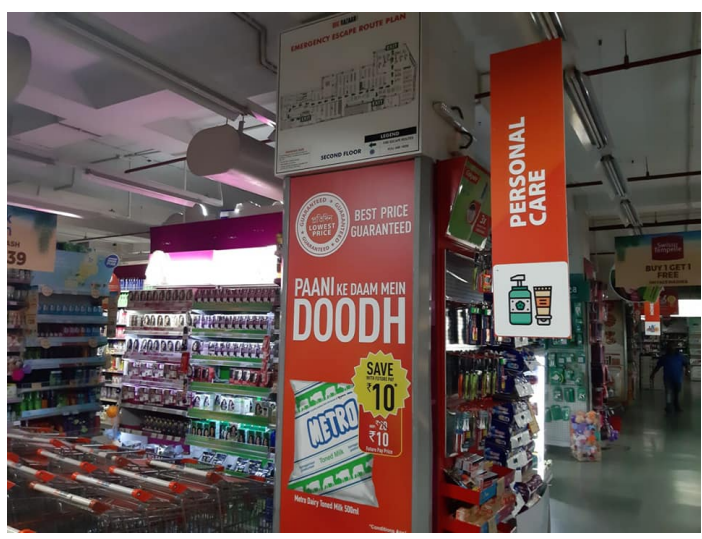

Fig. 3. Pictorial representation of the Personal Care Area

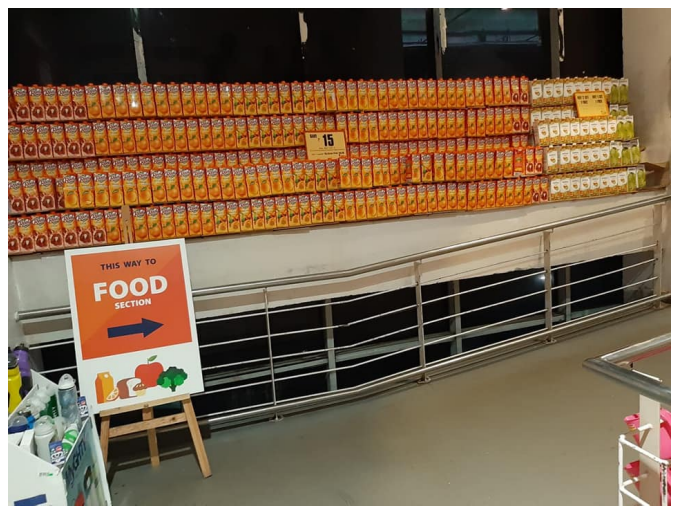

Fig 4. Arrow present in the labels to show direction of the Food section

Along with the labels there were arrows with the labels so that shoppers knew which way to go (Fig. 4). There were arrows directing the shoppers to the washroom, billing counters and exit (Fig 5). Many individuals with autism like to carry a 'to do list.' Big Bazaar created a lovely booklet where the shoppers could list the items they needed to buy (Fig 6). One of the prime barriers to inclusion for individuals 
with invisible disabilities is the attitudinal and societal barriers. As the disability cannot be seen society often fails to acknowledge the very existence of the disability leave alone provide supports. As autism Quiet Hour made shopping a happy experience more and more individuals with autism and their families visited the select outlets it provided a great opportunity for making autism visible among the public.

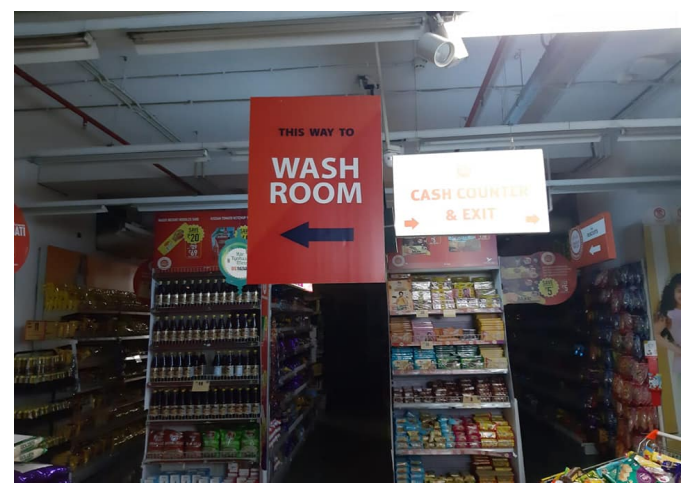

Fig. 5. Clear direction signs to the Washroom and Cash Counter \& Exit

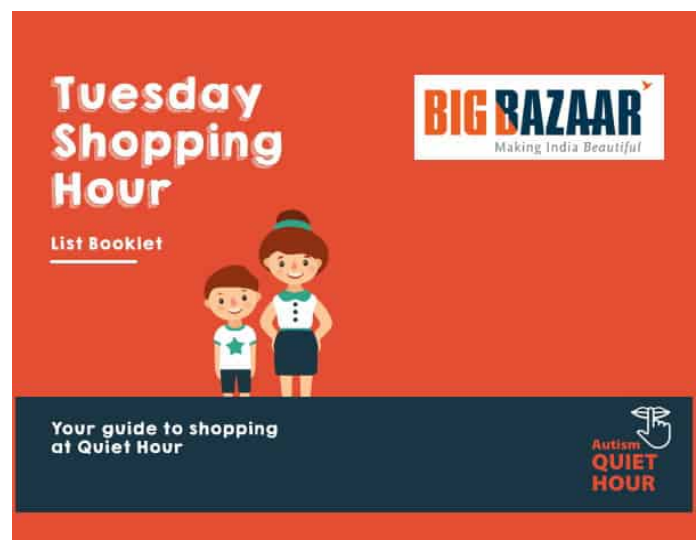

Fig. 6. Shopping List Booklet that was distributed to the shoppers

\section{Conclusion:}

Big Bazaar's Inclusion Lead believes that through the Quiet Hour stories, awareness about autism would be raised. It would lead to accepting and saluting the differences in people. The measures that were taken keeping the autistic population in mind were welcomed by many other shoppers who did not have autism. There were many shoppers, particularly the elderly who felt comfortable in the quiet environment where there was no announcement. As there was no music played it added to quiet and soothing environment. Clutter free aisles were a boon to many shoppers. This initiative was successful in the select outlets across India. It was the lockdown that hampered the initiative in 2020.

The Autism Quiet Hour was open to all shoppers. It provided an opportunity of shoppers with and without autism to observe each other. Interaction paves the way for acceptances. It is only when people observe and accept the inherent diversity can inclusion be fostered in the true sense. Inclusion apart, the initiative underlines a larger message that people with disabilities are an economic force capable of exercising choices. These reasonable accommodations that were provided ensured that these individuals could have a happy and meaningful role as a shopper. Their citizen rights as a shopper were upheld. Inclusion apart, the initiative underlines a larger message that people with disabilities are an economic force capable of exercising choices.

\section{Conflicts of Interest}

The authors declare that there are no conflicts of interest regarding the publication of this work.

\section{Acknowledgement}

The authors wish to thank all the staff members of the select outlets where Autism Quiet Hour was organized. The first author expresses her thanks to her son, Dipyaman Dey, an individual with autism, who introduced her to the intricate yet intriguing world with autism.

\section{Reference}

American Psychiatric Association. (2013). Diagnostic and Statistical Manual of Mental Disorders. $5^{\text {th }}$ Edition (DSM-5). Washington, DC.

Cohen, D.J. (1997). Handbook of Autism and Pervasive Developmental Disorders. $2^{\text {nd }}$ Edition., John Wiley and Sons, New York.

Daley, T. C. (2002). The Need for Crosscultural Research on the Pervasive Developmental Disorders. Transcultural Psychiatry, 39(4), 531-550.

Grinker, R. R. (2008). Unstrange Minds. New York: Basic books.

Walker, M. and Unterhalter, E. (2007) Amartya Sen's Capability Approach and Social Justice in Education, Palgrave Macmillan, New York. 